\title{
LA-UR- $00-3481$
}

Approved for public release; distribution is unlimited.

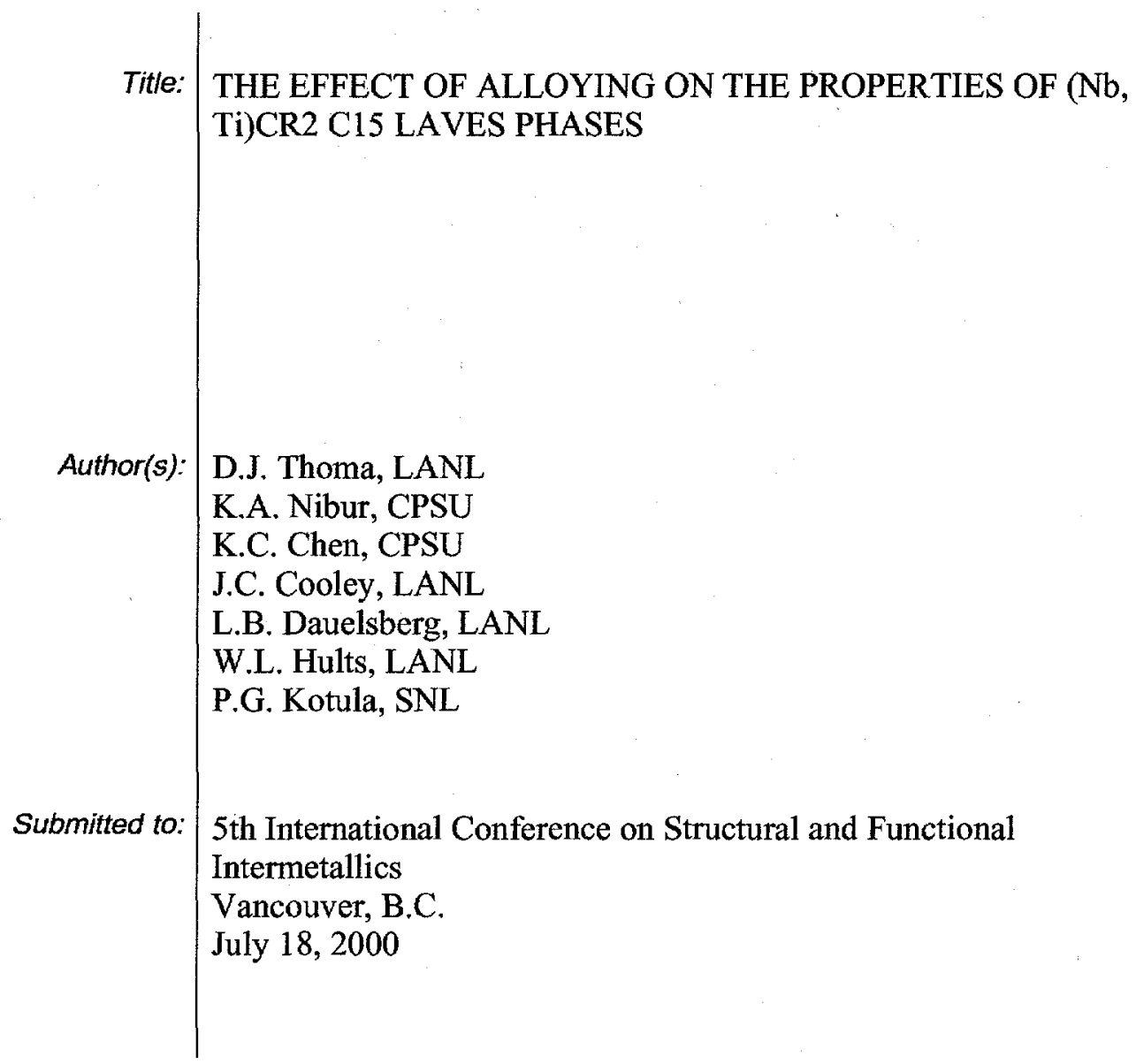

\section{Los Alamos}

NATIONAL LABORATORY

Los Alamos National Laboratory, an affirmative action/equal opportunity employer, is operated by the University of California for the U.S. Department of Energy under contract W-7405-ENG-36. By acceptance of this article, the publisher recognizes that the U.S. Government retains a nonexclusive, royalty-free license to publish or reproduce the published form of this contribution, or to allow others to do so, for U.S. Government purposes. Los Alamos National Laboratory requests that the publisher identify this article as work performed under the auspices of the U.S. Department of Energy. Los Alamos National Laboratory strongly supports academic freedom and a researcher's right to publish; as an institution, however, the Laboratory does not endorse the viewpoint of a publication or guarantee its technical correctness. 


\section{DISCLAIMER}

This report was prepared as an account of work sponsored by an agency of the United States Government. Neither the United States Government nor any agency thereof, nor any of their employees, make any warranty, express or implied, or assumes any legal liability or responsibility for the accuracy, completeness, or usefulness of any information, apparatus, product, or process disciosed, or represents that its use would not infringe privately owned rights. Reference herein to any specific commercial product, process, or service by trade name, trademark, manufacturer, or otherwise does not necessarily constitute or imply its endorsement, recommendation, or favoring by the United States Government or any agency thereof. The views and opinions of authors expressed herein do not necessarily state or reflect those of the United States Government or any agency thereof. 


\section{DISCLAIMER}

Portions of this document may be illegible in electronic image products. Images are produced from the best available original document. 


\title{
The Effect of Alloying on the Properties of $(\mathrm{Nb}, \mathrm{Ti}) \mathrm{Cr}_{2} \mathrm{C15}$ Laves Phases
}

D.J. Thoma ${ }^{1}$, K.A. Nibur ${ }^{2}$, K.C. Chen ${ }^{2}$, J.C. Cooley ${ }^{1}$, L.B. Dauelsberg ${ }^{1}$, W.L. Hults ${ }^{1}$, and P.G. Kotula ${ }^{3}$

${ }^{1}$ Los Alamos National Laboratory, Los Alamos, NM 87545

${ }^{2}$ California Polytechnic State University, Materials Engineering Department, San Luis Obispo, CA 93407

${ }^{3}$ Sandia National Laboratory, Albuquerque, NM, 87185-1405

\begin{abstract}
The effect of composition on the ternary $\left(\mathrm{NbCr}_{2}-\mathrm{TiCr}_{2}\right) \mathrm{C} 15$ phase properties has been investigated, focusing upon the defect structure, elastic properties, and mechanical behavior. The $\mathrm{C} 15$ phase field is continuous between $\mathrm{NbCr}_{2}-\mathrm{TiCr}_{2}$, with a maximum phase field width of at least 7 at.\% solubility. The defect mechanism is governed by anti-site constitutional defects for all alloys. Mechanically, the alloys display a maximum in hardness in the center of the ternary phase field (and a minimum of toughness). The ternary phase field has features that are characteristic of solid-solution strengthening mechanisms. Finally, the elastic properties indicate that the alloys become stiffer in the middle of the ternary phase field. The best compromise of properties occurs furthest from stoichiometry in the ternary phase field at the nominal composition of $\mathrm{Nb}_{19} \mathrm{Ti}_{19} \mathrm{Cr}_{62}$. The relationships between the defect structure, elastic properties, and mechanical response for the $\mathrm{C} 15$ phases are discussed using a combination of atomic size arguments and electronic structure analyses. From these relationships, alloy design strategies for $\mathrm{NbCr}_{2}$-based alloys are evaluated.
\end{abstract}




\section{Introduction}

Laves phases are the largest class of intermetallics. Over 360 binary phases have been identified, and considering both binary and ternary systems, over 900 phases exist [1]. Despite their abundance, the limitation of Laves phases for engineering applications results from the general observation that they display brittle behavior. Fabrication and utilization are limited by the inability to retain structural integrity. However, Laves phases, as a class of material, display encouraging high-temperature properties. Most notably, the alloys retain over $85 \%$ of their strength at half of their homologous melting temperature [2], and brittle to ductile transition temperatures occur at $0.65 \mathrm{~T}_{\mathrm{m}}$ [3]. Therefore, the challenge is to utilize the overwhelming abundance of Laves phases to tailor alloying opportunities for optimized mechanical properties. This requires a fundamental approach to alloying strategies and interpretation of the resultant properties.

Less than $25 \%$ of the known binary Laves phases exhibit a measurable range of solubility [1]. The C15 phases that do display solubility are those that exist between elemental metallic radii ratios $\left(R_{A} / R_{B}\right)$ of 1.1 and 1.35. In the $A B_{2}$ structure, the ideal size ratio of the atom sizes in the ordered structure is $\sqrt{ }(3 / 2) \approx 1.225$ as defined by near neighbor distances of the $A$ and $B$ atoms. Since Laves phases are predominantly metallic in bonding nature and largely governed by geometric space filling principles [4], solubility is related to the ability of A and B atoms to expand or contract so that the ideal ratio is approached [5]. Therefore, geometric rules have been developed to predict alloying behavior in Laves phases [1]. From this approach, it has been proposed that a simple and effective strategy for a broadened ternary alloy phase field would require $R_{A}>R_{C}>R_{B}$, where $C$ is the ternary addition to the $A B_{2}$ intermetallic.

Among the Laves phases, $\mathrm{NbCr}_{2}$ shows interesting promise for high-temperature structural applications. For example, $\mathrm{NbCr}_{2}$ has a high melting point $\left(1730^{\circ} \mathrm{C}\right)$ [6], reasonable density $(7.7 \mathrm{~g} / \mathrm{cm} 3)$, high strength [7], excellent creep behavior [8], and reasonable oxidation resistance (below $1000^{\circ} \mathrm{C}$ ). However, the material is brittle and requires modification to be a viable engineering material. Based upon the simple geometric principles, $T i\left(R_{N b}>R_{T i}>R_{C r}\right)$ would be an appropriate alloying addition to broaden the ternary phase field and define the property response as a function of composition. Since $\mathrm{Ti}$ is only slightly smaller than $\mathrm{Nb}, \mathrm{C} 15 \mathrm{NbCr}_{2}$ 
$\left(\mathrm{R}_{\mathrm{Nb}} / \mathrm{R}_{\mathrm{Cr}}=1.15\right)$ and $\mathrm{TiCr}_{2}\left(\mathrm{R}_{\mathrm{Ti}} / \mathrm{R}_{\mathrm{Cr}}=1.14\right)$ display a continuous phase field [9]. In addition, the C15 phase field displays a 7at.\% solubility range towards the $\mathrm{Cr}$-lean side in the room temperature ternary isotherm. The goal of this study is to interpret the influence of alloying on properties in the $\mathrm{NbCr}_{2}-\mathrm{TiCr}_{2} \mathrm{C} 15$ Laves phase field.

\section{Experimental Procedure}

Elemental $\mathrm{Nb}, \mathrm{Cr}$, and $\mathrm{Ti}$ with nominal purities of $99.9 \mathrm{at} . \%, 99.99$ at.\%, and $99.99 \mathrm{at} . \%$ respectively, were arc-cast into eight different 30 gram ingots with varying nomimal compositions (Table I). The ingots were arc-cast on a water-cooled copper hearth. The arcmelting chamber was evacuated to $0.5 \mathrm{~Pa}$ and purged at least three times with high purity argon. Titanium buttons were melted as oxygen getters before each ingot melting. The ingots were inverted and melted 10 times to ensure chemical uniformity.

Heat-treatments of the ingots consisted of 48 hours at $1300^{\circ} \mathrm{C}, 100$ hours at $1400^{\circ} \mathrm{C}$, and 100 hours at $1200^{\circ} \mathrm{C}$, followed by a $1^{\circ} \mathrm{C} / \mathrm{min}$. furnace cool. The first step homogenizes the ingots before any melting of segregated regions occurred. The $1400^{\circ} \mathrm{C}$ step provides more complete chemical homogeneity, and the $1200^{\circ} \mathrm{C}$ treatment is used to homogenize below the expected polytype transformation (C14 to $\mathrm{C} 15$ ). All ingots were wrapped first with $\mathrm{Nb}$ foil and then $\mathrm{Ti}$ foil. The furnace system was evacuated (to $0.5 \mathrm{~Pa}$ ) and purged three times before heating, with the heat-treatment occurring in a flowing environment of high-purity argon. A boat of Ti chips was placed in the hot-zone of the furnace upstream from the sample as an oxygen getter for the incoming argon stream.

The compositions of the ingots were evaluated using electron microprobe analyses. Standardbased analyses were used, with examinations performed at an accelerating voltage of $15 \mathrm{kV}$. Lattice parameters were determined using $\mathrm{Cu} K \alpha$ radiation. Silicon standards were mixed with the samples and cell refinement analyses were used to determine the lattice parameters.

The mechanical properties were surveyed using microhardness indentation. A Vickers hardness indenter was used with a 500 gram load and a dwell time of 15 seconds. Twenty measurements were made on each sample. Furthermore, toughness was evaluated by examining the crack 
lengths made during indentation. Scanning electron microscopy was used to measure the crack lengths, and the toughness was determined using the equation [10]:

$$
K=0.016\left(\frac{E}{H}\right)^{1 / 2}\left(\frac{P}{c^{3 / 2}}\right)
$$

In the equation, $\mathrm{E}$ is the Young's modulus, $\mathrm{H}$ is the hardness, $\mathrm{P}$ is the applied load, and $\mathrm{c}$ is the average crack length.

Resonant ultrasound spectroscopy (RUS) $[11,12]$ was used to study the room temperature elastic properties of the polycrystalline alloys. The specimens were cut into rectangular parallelpipeds (roughly $2 \times 3 \times 4 \mathrm{~mm}$ ) and ground to final finish using 800 grit SiC paper. The mass-densities of the specimens were determined from their dimensions and masses. For this study, 15 to 30 resonant peaks from $0.2 \mathrm{MHz}$ to $1.5 \mathrm{MHz}$ were used for each sample to determine the elastic constants. In the measurement, the samples were assumed to be isotropic and only two elastic constants, $c_{11}$ and $c_{44}$, were fitted in the RUS procedures. In this case, the bulk modulus B, shear modulus G, Young's modulus E, and Poisson's ratio v, can be obtained through

$$
\begin{aligned}
& B=\frac{1}{3}\left(3 c_{11}-4 c_{44}\right) \\
& G=c_{44} \\
& E=\frac{c_{44}\left(3 c_{11}-4 c_{44}\right)}{c_{11}-c_{44}} \\
& v=\frac{1}{2} \frac{c_{11}-2 c_{44}}{c_{11}-c_{44}}
\end{aligned}
$$

The overall r.m.s errors for the measured RUS peaks were less than $0.5 \%$, indicating an acceptable fit to the experimental elastic moduli. 


\section{Results}

\section{Compositions and Lattice Parameters}

A ternary isotherm of the $\mathrm{Nb}-\mathrm{Cr}$ - Ti phase diagram (at $950^{\circ} \mathrm{C}$ ) is shown in Figure 1 [9]. The nominal compositions of the alloys are displayed in the $\mathrm{C} 15$ phase field, illustrating the isoplethal set of alloys $\left[\left(\mathrm{Nb}_{33-\mathrm{x}} \mathrm{Ti}_{\mathrm{x}}\right) \mathrm{Cr}_{67}\right]$ and the constant $\mathrm{Nb} / \mathrm{Ti}$ plethal alloys $\left[\left(\mathrm{Nb}_{\mathrm{x}} \mathrm{Ti}_{\mathrm{x}}\right) \mathrm{Cr}_{67-2 \mathrm{x}}\right]$. Based upon the phase field, the primary constitutional defect would be expected to be a substitution of $\mathrm{Nb}$ and $\mathrm{Ti}$ on $\mathrm{A}$ sub-lattice sites.

The experimental compositions of the samples are compared to the nominal compositions in Table I. In all but one sample, the $\mathrm{Cr}$ and $\mathrm{Ti}$ content was slightly less than the intended values, but overall, the compositional control was satisfactory. The lattice parameters are also given in Table I. When the lattice parameters are plotted against these compositions, systematic trends are evident (Figure 2). The lattice parameters of the samples along the chromium isopleth $\left\{\left(\mathrm{Nb}_{33-\mathrm{x}} \mathrm{Ti}_{\mathbf{x}}\right) \mathrm{Cr}_{67}\right\}$ illustrate a slight negative deviation between $\mathrm{NbCr}_{2}$ and $\mathrm{TiCr}_{2}$. The values for $\mathrm{NbCr}_{2}$ [6] and $\mathrm{TiCr}_{2}$ [13] were taken from the literature as was the data for $\mathrm{Nb}_{9.5} \mathrm{Ti}_{26} \mathrm{Cr}_{64.5}$ [14]. The negative deviation from an ideal rule of mixtures suggests tighter binding when $\mathrm{Nb}$ and $\mathrm{Ti}$ occupy the A sub-lattice as compared to the binary phases.

The lattice parameters of the samples along the constant $\mathrm{Nb} / \mathrm{Ti}$ plethal section $\left[\left(\mathrm{Nb}_{\mathrm{x}} \mathrm{Ti}_{\mathrm{x}}\right) \mathrm{Cr}_{67-2 \mathrm{x}}\right]$ increase rapidly as the $\mathrm{Cr}$ content decreases ( $\mathrm{Ti}$ content increases). This suggests that the operative defect mechanism is $\mathrm{Nb}$ and/or $\mathrm{Ti}$ substituting onto the $\mathrm{B}$ sub-lattice. In fact, this result is consistent with a study that used Atom Location by Channeling Enhanced MIcroanlaysis (ALCHEMI) [15]. This study suggested that, on the Cr-lean side of the constant $\mathrm{Nb} / \mathrm{Ti}$ plethal section, Ti preferentially substitutes onto the $\mathrm{B}$ sub-lattice (as opposed to $\mathrm{Nb}$ ). On the $\mathrm{A}$ sublattice sites, only $\mathrm{Nb}$ and $\mathrm{Ti}$ occupy the sites. 


\section{Hardness Properties}

The hardness data along the $\mathrm{Cr}$ isopleth (Figure 3) and the constant $\mathrm{Nb} / \mathrm{Ti}$ plethal section (Figure 4) indicates subtle increases in hardness as a function of increasing Ti content. As titanium substitutes for $\mathrm{Nb}$, the hardness increases slightly towards the middle of the phase field. From the middle of the $\mathrm{NbCr}_{2}-\mathrm{TiCr}_{2}$ isopleth, substitution of $\mathrm{Ti}$ onto the $\mathrm{B}$ sub-lattice further increases the hardness. The trend suggests that the further away it is away from stoichiometry, the harder the $\mathrm{C} 15$ phase becomes.

In contrast to the hardness data, the toughness data along the isoplethal section are relatively constant (Figure 5). However, along the constant $\mathrm{Nb} / \mathrm{Ti}$ plethal section, the toughness appears to increase slightly with increasing Ti content (decreasing $\mathrm{Cr}$ content). Interestingly, the standard deviation increases substantially. Nonetheless, the monolithic C15 phase becomes slightly harder as anti-site substitution on the A and B sites is increased.

\section{Elastic Properties}

The elastic properties of the alloys are given in Table II along with the values for $\mathrm{NbCr}_{2}[16]$ and $\mathrm{TiCr}_{2}$ [17]. The data for sample \#1 could not be evaluated because of the inability to obtain a good fit of the data. It is possible that microcracks deteriorated the ability to determine elastic constants with reasonable fits. In addition, the data for sample \#6 may be experiencing the same difficulties. Nonetheless, the properties, in general, are within approximately $10 \%$ of each other, illustrating that the elastic properties do not change remarkably within the ternary $\mathrm{C} 15$ phase field. The Youngs's modulus is $\sim 210 \mathrm{GPa}$ for all of the alloys, the Poisson's ratio is around 0.3 , and the shear modulus is approximately $80 \mathrm{GPa}$. However, subtle trends do exist. The most notable are the shear and Young's modulii. Along the $\mathrm{Cr}$ isopleth, the shear modulus display a positive deviation from a rule of mixtures, whereas the Young's modulus roughly follows a rule of mixtures (Figure 6). Along the constant $\mathrm{Nb} / \mathrm{Ti}$ plethal section, the elastic properties systematically decrease as the Ti content increases ( $\mathrm{Cr}$ content decreases). Thus, as anti-site substitution increases on the B sub-lattice, the alloys become less stiff. 


\section{Discussion}

\section{Phase Stability and Defect Structure}

The phase diagram and lattice parameters, coupled with ALCHEMI results, clearly indicate that $\mathrm{Ti}$ primarily substitutes for $\mathrm{Nb}$ in the $\mathrm{C} 15$ phase field of the $\mathrm{Nb}-\mathrm{Cr}$-Ti ternary system. This result is expected since the atomic radii of metallic $\mathrm{Nb}(\mathrm{R}=1.468)$ and $\mathrm{Ti}(\mathrm{R}=1.462)$ are similar. The stability and adundance of Laves phases have historically been attributed to geometric space filling principles, and the results of this study are certainly consistent with this view. However, from size arguments alone, it is easier to conceptualize a broader phase field on the $\mathrm{Cr}$-rich side stoichiometry as contrasted to the experimental observation of enhanced solubility on the Cr-lean side of the $\mathrm{Nb} / \mathrm{Ti}$ plethal section. For example, assuming a hard-ball model, a smaller $\mathrm{Cr}$ atom $(\mathrm{R}=1.282)$ can be "packed" into an A sub-lattice more easily than a ( $\mathrm{Nb}, \mathrm{Ti})$ atom on a B sublattice site. This contradiction to a size rule can be interpreted through a consideration of the electronic structure. First-principles electronic and total energy calculations show that the Fermi energy of $\mathrm{C} 15 \mathrm{NbCr}_{2}$ reaches such a level that substantial amount of antibonding electronic states of the system are occupied [18,19]. Since this is not an energetically favorable condition, it is possible that alloying methodologies that lower the valence electron contributions should be favored [20]. Titanium has a lower valence state than niobium, and niobium has a lower valence state than chromium. Therefore, from an electronic structure argument, $\mathrm{Ti}$ or $\mathrm{Nb}$ occupancy of $\mathrm{Cr}$ atom sites may reduce the number of filled anti-bonding states. Accordingly, the Fermi level will be located at a lower density of states. The more energetically favorable electronic structure may account for solubility on the Cr-lean side of stoichiometry, despite the fact that the $\mathrm{Nb}$ or $\mathrm{Ti}$ atom is larger than the $\mathrm{Cr}$ atom. In fact, this electronic argument may provide insight into the observed result from ALCHEMI experiments that $\mathrm{Ti}$ is preferential to $\mathrm{Nb}$ in substituting onto the B sub-lattice. Since $\mathrm{Ti}$ has a lower valence than $\mathrm{Nb}$, it would be a more efficient substitution to provide a more energetically favorable electronic structure. Details of the $\mathrm{TiCr}_{2}$ electronic structure would substantiate this hypothesis.

\section{Mechanical Behavior}

Due to the specific arrangement of atoms, deformation involving simple planar slip is unlikely and a "synchroshear" or "zonal slip" mechanism involving cooperative movement between planes of atoms may be required in Laves phases [21-23]. The mechanism of synchroshear is 
graphically illustrated in Figure 9. The deformable layer in the structure has been proposed to consist of the $\alpha c \beta$ "sandwich". The smaller B atoms shear by $1 / 6[-211]$ while synchronously, the larger $\mathrm{A}$ atoms shear by $1 / 6[-1-12]$. In other words, the smaller atoms move from the illustrated $c$-site to the $b$-site while the larger atoms move from the $\beta$-site to the $\gamma$-site. The synchroshear process has been used to interpret slip, twinning, stacking faults, and phase transformations in Laves phases.

From the interpretation of synchroshear, an effective alloying addition would consist of a smaller atom onto the A sub-lattice site. This has been postulated to enhance shear deformation in $\mathrm{C} 15$ structures [24], thus making $\mathrm{Ti}$ an attractive addition for $\mathrm{Nb}$ to provide more deformability in $\mathrm{NbCr}_{2}$. However, the hardness increases and the toughness does not increase substantially as $\mathrm{Ti}$ substitutes for $\mathrm{Nb}$. These results may be correlated to the lattice parameters, where a negative deviation from a rule of mixtures exist. The lattice actually contracts, providing higher packing in the deformable $\alpha c \beta$ sequence than expected from a hard sphere viewpoint. The tighter binding may translate to less slip during deformation. The tighter binding is also reflected in the higher shear modulus (a positive deviation from a rule of mixtures) with respect to the terminal binary phases.

The size arguments on deformation have been used for B site occupancy [19]. In $\mathrm{Nb}(\mathrm{Cr}, \mathrm{V})_{2}, \mathrm{~V}$ was found to preferentially subsititute on the B-sublattice, and since $\mathrm{R}_{\mathrm{Cr}}<\mathrm{R}_{\mathrm{V}}$, the packing density of atoms within the deformable $\alpha c \beta$ sandwich would increase, therefore "locking" the deformation mechanism. Specifically, for $\mathrm{Nb}_{33} \mathrm{Cr}_{42} \mathrm{~V}_{25}$ the lattice parameter changed only $1 \%$ as compared to $\mathrm{NbCr}_{2}$, but the elemental vanadium atomic radius was $5 \%$ larger than chromium. This resulted in higher strength, higher shear modulus, lower fracture toughness, and a higher brittle to ductile transition temperature. However, with $\mathrm{Ti}$ substitution onto the $\mathrm{Cr}$ lattice, this trend is not evident. Elemental $\mathrm{Ti}$ is $14 \%$ larger than $\mathrm{Cr}$, and the lattice parameter only changes $0.5 \%$ between the nominal compositions of $\mathrm{Nb}_{16} \mathrm{Ti}_{16} \mathrm{Cr}_{68}$ and $\mathrm{Nb}_{19} \mathrm{Ti}_{19} \mathrm{Cr}_{62}$. Thus, making the same argument with V substitution, the deformation mechanism should be even more restricted than with the case of vanadium substitutions onto $\mathrm{Cr}$ sites. The data illustrate that the alloys along the constant $\mathrm{Nb} / \mathrm{Ti}$ plethal section become harder, but the elastic moduli decrease and the 
toughness increase. This is the most intriguing aspect of this study, and will be the focus of future studies.

\section{Elastic Properties}

Overall, the elastic properties of the $(\mathrm{Nb}, \mathrm{Ti}) \mathrm{Cr}_{2}$ Laves phases are interesting as compared to other intermetallic systems. The shear moduli are comparable to nickel aluminides and higher than titanium aluminides, and much lower than transition metal silicides. The shear modulus values for the ternary alloys suggest a maximum in the middle of the phase field, and a decreasing trend as the alloys become Cr-lean. All ternary alloys had a slightly higher shear modulus as compared to the binary $\mathrm{C} 15$ phases.

The Poisson's ratios of the alloys were all approximately 0.3 . This number reflects the volume change during uniaxial deformation. If $v$ is $1 / 2$, no volume change occurs. Furthermore, the Poisson's ratio provides information about the directionality of bonding forces. A Poisson's ration of $\mathrm{v}=0.5$ is an upper limit that corresponds to infinite elastic isotropy, while a value of 0.25 is a lower limit for central-force polycrystals. The Poisson's ratios in this study are higher than aluminides and silicides, suggesting less-directional interatomic forces than those of other hightemperature structural intermetallics. However, all values were lower than the measured values of $\mathrm{NbCr}_{2}$, suggesting that increased bonding directionality may be occurring with $\mathrm{Ti}$ additions.

\section{Alloying Strategies}

The methodology to choose alloying elements based upon geometric considerations is an effective strategy for a first level attempt in selecting elements for property modification. For Laves phases; the simple requirement that $R_{A}>R_{C}>R_{B}$ (where $C$ is the ternary alloying element to the $\mathrm{AB}_{2}$ Laves phase) has proven to be consistent for large extensions of the ternary phase field. These geometric considerations are founded upon more detailed investigations on the occurrence of solubility in Laves phases. The alloying selections can be further refined with a fundamental understanding of the electronic structure, with valence states being a useful guide for siteoccupancy. Of course, this requires that reasonable estimates of the Fermi level energy positions with respect to the total density of states are made. In all of these estimates, it is a reasonable 
assumption that only anti-site substitution (as opposed to constitutional vacancies) occurs in Laves phases since contrary information is almost non-existent.

With useful tactics on how to alloy the Laves phase, specific property modifications can be addressed. To address deformability in $\mathrm{C} 15$ phases, the assumption that synchroshear is the operative defect mechanism is a guiding principle. Since deformation occurs in the $\alpha c \beta$ stacking sandwich, reduction of the activation barriers and Burger's vectors is an appropriate goal, and this may be most easily obtained by substituting a smaller $\mathrm{C}$ atom onto an $\mathrm{A}$ site. From a hard sphere concept, this would facilitate synchroshear. However, although Ti is smaller than $\mathrm{Nb}$, the lattice collapses with Ti substitutions onto the $\mathrm{Nb}$ sites, and atom binding appears to be tighter and slightly more directional. As a result, significant enhancement of the synchroshear process does not occur along the isoplethal section. A careful balance between site occupancy and packing efficiency is required and apparently is not achieved along the isopleth. Other features such as stacking fault energy need more investigation to elucidate mechanical response, and efforts are underway to achieve this goal.

The most useful alloying result in $\mathrm{NbCr}_{2}-\mathrm{TiCr}_{2}$ alloys occurs away from $\mathrm{Cr}$ stoichiomety. As alloying in the ternary phase field is maximized (i.e., substitution of Ti on both A and B sites), the alloys display higher hardness and the increased toughness. Moreover, the elastic moduli gradually decrease with respect to deviations from stoichiometry of the isoplethal alloys. This is an interesting observation in that a similar event may be occurring in $\mathrm{HfV}_{2}+\mathrm{Nb}$ [24], with $\mathrm{Nb}$ substituting preferentially on $\mathrm{Hf}$ sites, but also on $\mathrm{V}$ sites [15], resulting in plastic deformation at room temperature. This raises the notion that deformability may be linked to site substitutions on both sites (not just the A site) with a corresponding decrease in the order parameter. With this information, the best choice of an alloy to produce a dual-phase microstructure (bcc/C15 phases) would be alloys comprised of the $\mathrm{Nb}_{20} \mathrm{Ti}_{20} \mathrm{Cr}_{60}$ (maximum limit of the phase field) and the ( $\mathrm{Nb}, \mathrm{Ti})$ base bcc solid solution. In fact, recent studies have shown that these alloys have encouraging combinations of high-temperature strength [7] and room temperature toughness [25]. Varying volume fractions of the Laves phase with respect to a bcc $(\mathrm{Nb}, \mathrm{Ti})$ base matrix are currently being explored to expand upon this possiblity. 


\section{Conclusions}

The effect of alloying in the $\mathrm{NbCr}_{2}-\mathrm{TiCr}_{2} \mathrm{C} 15$ phase field has been explored. The defect mechanisms and phase stability have been examined, and the resulting mechanical behavior and elastic properties were investigated. Five conclusions can be drawn from this work:

1) The ternary phase field is continuous between $\mathrm{NbCr}_{2}$ and $\mathrm{TiCr}_{2}$, with a $7 \%$ phase field extension to Cr-lean alloys. In all cases, the defect mechanism appears to be anti-site substitution, and the alloying can be interpreted based upon geometric space filling principles coupled with electronic structure arguments.

2) The lattice parameters along the $\left(\mathrm{Nb}_{33-\mathrm{x}} \mathrm{Ti}_{\mathrm{x}}\right) \mathrm{Cr}_{67}$ isoplethal section show a negative deviation from a linear rule of mixtures (suggesting tighter binding than the binary phases), and lattice parameters along the constant $\mathrm{Nb} / \mathrm{Ti}$ plethal section $\left[\left(\mathrm{Nb}_{\mathrm{x}} \mathrm{Ti}_{\mathrm{x}}\right) \mathrm{Cr}_{67-2 x}\right]$ increase rapidly, consistent with anti-site substitutions.

3) Titanium additions to $\mathrm{NbCr}_{2}$ increase the hardness along both the $\mathrm{Cr}$ isoplethal section and the constant $\mathrm{Nb} / \mathrm{Ti}$ plethal section. The toughness increased only along the constant $\mathrm{Nb} / \mathrm{Ti}$ plethal section.

4) With Ti additions, the elastic properties all increase with respect to $\mathrm{NbCr}_{2}$, with all Poisson's ratios being slightly less than $\mathrm{NbCr}_{2}$ ( 0.3 vs 0.34 ). The shear moduli along the $\mathrm{Cr}$ isoplethal section showed a positive deviation with respect to a linear rule of mixtures between $\mathrm{NbCr}_{2}$ and $\mathrm{TiCr}_{2}$, correlating with the increased hardness and the negative deviation of the lattice parameters (with respect to a rule of mixtures).

5) The elastic moduli gradually decreased along the constant $\mathrm{Nb} / \mathrm{Ti}$ plethal section.

All of these results suggest that the optimized combination of properties exist in the $\mathrm{C} 15$ phase that was furthest from $\mathrm{NbCr}_{2}$ stoichiometry $\left(\mathrm{Nb}_{19} \mathrm{Cr}_{19} \mathrm{Ti}_{62}\right)$.

\section{Acknowledgements}

Support from the Department of Energy-Office of Basic Energy Sciences (Division of Materials Sciences) is gratefully acknowledged. We would also like to thank John Balog and Richard Less for their patient machining of RUS specimens. Finally, the efforts of Ann Kelly for metallographic preparations and the insight provided by Dr. Robert D. Field are appreciated. 


\section{References}

1 D.J. Thoma, and J.H. Perepezko, J. of Alloys and Compounds 224330 (1995).

2 R.L. Fleischer, MRS Symp. Proc. 133305 (1989).

3 D.J. Thoma, F. Chu, P. Peralta, P.G. Kotula, K.C. Chen and T.E. Mitchell, Mat. Sci. \& Eng. A 239-240 251 (1997).

4 F. Laves, in "Theory of Alloy Phases", (ASM, Cleveland, OH) 123 (1956).

5 A.E. Dwight, Trans. ASM 53479 (1961).

6 D.J. Thoma, and J.H. Perepezko, Mater. Sci. \& Eng. A 15697 (1992).

7 K.C. Chen, P.G. Kotula, C.M. Cady, M.E. Mauro, and D.J. Thoma, MRS Symp. Proc. 552 KK7.4.1 (1999).

8 D.L. Anton, and D.M. Shah, MRS Symp. Proc. 213733 (1991).

9 D.J. Thoma and J.H. Perepezko, in "Experimental Methods of Phase Diagram Determination", J.E. Morral, R.S. Schiffman, and S.M. Merchant, eds., (TMS, Warrendale, PA) 43 (1993).

10 G. R. Anstis, P. Chantyikul, B. R. Lawn, and D. B. Marshall, J. Amer. Cera. Soc., 64, 533 (1981).

11 A. Migliori, et al. Physica B 183, 1 (1993).

12 F. Chu, M. Lei, A. Migliori, S. P. Chen, and T. E. Mitchell, Phil. Mag. B 70, 867 (1994).

13 K.C. Chen, S.M. Allen, and J.D. Livingston, Materials Science and Engineering $\mathbf{A 2 4 2} 163$ (1998).

14 D.J. Thoma and J.H. Perepezko, Materials Science Forum, 179-181 769 (1995).

15 P.G. Kotula, I. M. Anderson, F. Chu, D. J. Thoma, J. Bentley, and T. E. Mitchell, MRS Symp. Proc. 460617 (1997).

16 F. Chu, Y. He, D.J. Thoma and T.E. Mitchell, Scripta Metall. et Mater, 33 \#8, 1295 (1995).

17 F. Chu and D.J. Thoma, unpublished data.

18 A. Ormeci, F. Chu, J. M. Wills, T. E. Mitchell, R. C. Albers, D. J. Thoma, and S. P. Chen, Phys. Rev. B, 54, 12753 (1996).

19 F. Chu, D. J. Thoma, P. G. Kotula, S. Gerstl, T. E. Mitchell, I. M. Anderson, and J. Bentley, Acta Mater., 461759 (1998).

20 A. Ormeci, S.P. Chen, J.M. Wills, and R.C. Albers, MRS Symp. Proc. 552 KK8.30.1 (1999).

21 C.W. Allen, K.C. Liao, and A.E. Miller, J. Less-Common Metals 52109 (1977).

22 J.D. Livingston, Phys. Stat. Sol. (a) 131415 (1992).

23 F. Chu and D.P. Pope, Mater. Sci. \& Eng. A 17039 (1993).

24 F. Chu and D.P. Pope, MRS Symp. Proc 288561 (1993).

25 D.L. Davidson and K.S. Chan, Scripta Mater. 38(\#7) 1155 (1998). 


\section{Figure Captions}

Figure 1 - The ternary phase diagram for Nb-Cr-Ti [9]. Shown in the $\mathrm{NbCr}_{2}-\mathrm{TiCr}_{2} \mathrm{C} 15$ phase field are the compositions of the alloys investigated in this study. The horizontal row of alloys are along the $\left(\mathrm{Nb}_{33-\mathrm{x}} \mathrm{Ti}_{\mathrm{x}}\right) \mathrm{Cr}_{67}$ isopleth, and the vertical row of alloys are along the $\left(\mathrm{Nb}_{\mathrm{x}} \mathrm{Ti}_{\mathrm{x}}\right) \mathrm{Cr}_{67-2 \mathrm{x}}$ constant $\mathrm{Nb} / \mathrm{Ti}$ plethal section.

Figure 2 - The lattice parameters for the $\mathrm{C} 15$ Laves phases. The alloys along the $\left(\mathrm{Nb}_{33-\mathrm{x}} \mathrm{Ti}_{\mathrm{x}}\right) \mathrm{Cr}_{67}$ isopleth display a negative deviation from a linear rule of mixtures. The alloys along the $\left(\mathrm{Nb}_{\mathrm{x}} \mathrm{Ti}_{\mathrm{x}}\right) \mathrm{Cr}_{67-2 \mathrm{x}}$ constant $\mathrm{Nb} / \mathrm{Ti}$ plethal section increase rapidly with increasing Ti content. The data for $\mathrm{NbCr}_{2}$ [6], $\mathrm{TiCr}_{2}$ [13], and $\mathrm{Nb}_{9.5} \mathrm{Ti}_{26} \mathrm{Cr}_{65.5}$ [14] were taken from the literature.

Figure 3 - The Vickers hardness data as a function of Ti content along the $\left(\mathrm{Nb}_{33-\mathrm{x}} \mathrm{Ti}_{\mathrm{x}}\right) \mathrm{Cr}_{67}$ isopleth.

Figure 4 - The Vickers hardness data as a function of Ti content along the $\left(\mathrm{Nb}_{\mathbf{x}} \mathrm{Ti}_{\mathbf{x}}\right) \mathrm{Cr}_{67-2 \mathrm{x}}$ constant $\mathrm{Nb} / \mathrm{Ti}$ plethal section.

Figure 5 - The toughness data (determined from crack lengths developed during indentation) along the $\left(\mathrm{Nb}_{33-\mathrm{x}} \mathrm{Ti}_{\mathrm{x}}\right) \mathrm{Cr}_{67}$ isopleth.

Figure 6 - The toughness data (determined from crack lengths developed during indentation) along the $\left(\mathrm{Nb}_{\mathbf{x}} \mathrm{Ti}_{\mathrm{x}}\right) \mathrm{Cr}_{67-2 \mathrm{x}}$ constant $\mathrm{Nb} / \mathrm{Ti}$ plethal section.

Figure 7 - The shear and Young's moduli for alloys along the $\left(\mathrm{Nb}_{33-\mathrm{x}} \mathrm{Ti}_{\mathrm{x}}\right) \mathrm{Cr}_{67}$ isopleth. The data for $\mathrm{NbCr}_{2}$ is from [16], and the data for $\mathrm{TiCr}_{2}$ is from [17].

Figure 8 - The shear and Young's moduli for alloys along the $\left(\mathrm{Nb}_{\mathrm{x}} \mathrm{Ti}_{\mathrm{x}}\right) \mathrm{Cr}_{67-2 \mathrm{x}}$ constant $\mathrm{Nb} / \mathrm{Ti}$ plethal section.

Figure 9 - The deformable $\alpha c \beta$ stacking sandwich in the C15 structure (redrawn from [ ]). 
Table I - List of nominal compositions, actual compositions (determined from microprobe studies) and lattice parameters of the alloys used.

\begin{tabular}{|c|c|c|c|c|c|c|c|}
\hline \multirow{2}{*}{$\begin{array}{l}\text { Sample } \\
\text { Number }\end{array}$} & \multicolumn{3}{|c|}{ Nominal Composition (at.\%) } & \multicolumn{3}{|c|}{ Measured Composition (at.\%) } & \multirow{2}{*}{$\begin{array}{c}\text { Lattice Parameter } \\
\text { (Angstroms) }\end{array}$} \\
\hline & $\mathrm{Nb}$ & $\mathrm{Ti}$ & $\mathrm{Cr}$ & $\mathrm{Nb}$ & $\mathrm{Ti}$ & $\mathrm{Cr}$ & \\
\hline 1 & 28 & 5 & 67 & 29.8 & 4.0 & 66.2 & $6.9778 \pm 0.0001$ \\
\hline 2 & 23 & 10 & 67 & 24.8 & 9.2 & 66.0 & $6.9675 \pm 0.0002$ \\
\hline 3 & 18 & 15 & 67 & 19.8 & 14.0 & 66.2 & $6.9583 \pm 0.0001$ \\
\hline 4 & 13 & 20 & 67 & 14.5 & 19.5 & 66.0 & $6.9495 \pm 0.0002$ \\
\hline 5 & 16 & 16 & 68 & 18.4 & 15.6 & 66.0 & $6.9556 \pm 0.0001$ \\
\hline 6 & 17 & 17 & 66 & 18.1 & 16.1 & 65.8 & $6.9594 \pm 0.0001$ \\
\hline 7 & 18 & 18 & 64 & 19.4 & 16.9 & 63.7 & $6.9717 \pm 0.0001$ \\
\hline 8 & 19 & 19 & 62 & 20.1 & 17.3 & 62.6 & $6.9882 \pm 0.0001$ \\
\hline
\end{tabular}


Table II - List of elastic properties for the alloys studied

\begin{tabular}{|c|c|c|c|c|c|}
\hline $\begin{array}{c}\text { Sample } \\
\text { Number }\end{array}$ & $\begin{array}{c}\text { Nominal } \\
\text { Composition } \\
\text { Nb-Ti-Cr (at.\%) }\end{array}$ & $\begin{array}{c}\text { Young's } \\
\text { Modulus, E } \\
(\mathrm{GPa})\end{array}$ & $\begin{array}{c}\text { Shear } \\
\text { Modulus, G } \\
(\mathrm{GPa})\end{array}$ & $\begin{array}{c}\text { Bulk } \\
\text { Modulus, B } \\
(\mathrm{GPa})\end{array}$ & $\begin{array}{c}\text { Poisson's } \\
\text { Ratio, } v\end{array}$ \\
\hline $\mathrm{NbCr}_{2}{ }^{*}$ & & 214.1 & 79.6 & 229.4 & 0.34 \\
\hline 2 & $23-10-67$ & 212.4 & 82.0 & 172.9 & 0.30 \\
\hline 3 & $18-15-67$ & 212.9 & 83.3 & 159.8 & 0.28 \\
\hline 4 & $13-20-67$ & 210.2 & 82.1 & 159.4 & 0.28 \\
\hline $\mathrm{TiCr}_{2}{ }^{* *}$ & & 203.9 & 78.8 & 165.5 & 0.29 \\
\hline 5 & $16-16-68$ & 219.6 & 84.6 & 180.8 & 0.30 \\
\hline 6 & $17-17-66$ & 219.0 & 83.1 & 200.0 & 0.32 \\
\hline 7 & $18-18-64$ & 214.8 & 83.0 & 174.0 & 0.29 \\
\hline 8 & $19-19-62$ & 213.0 & 82.6 & 168.7 & 0.29 \\
\hline
\end{tabular}

* from [14]

** from $[15]$ 


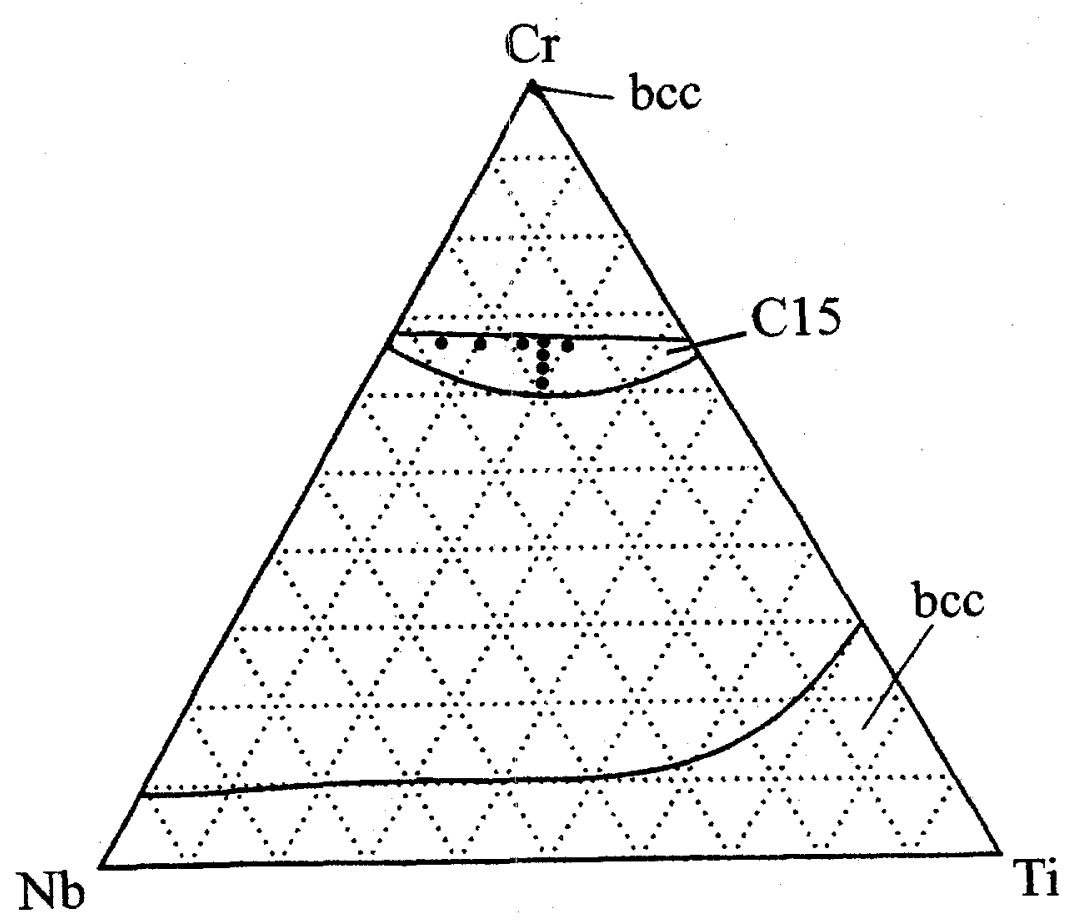




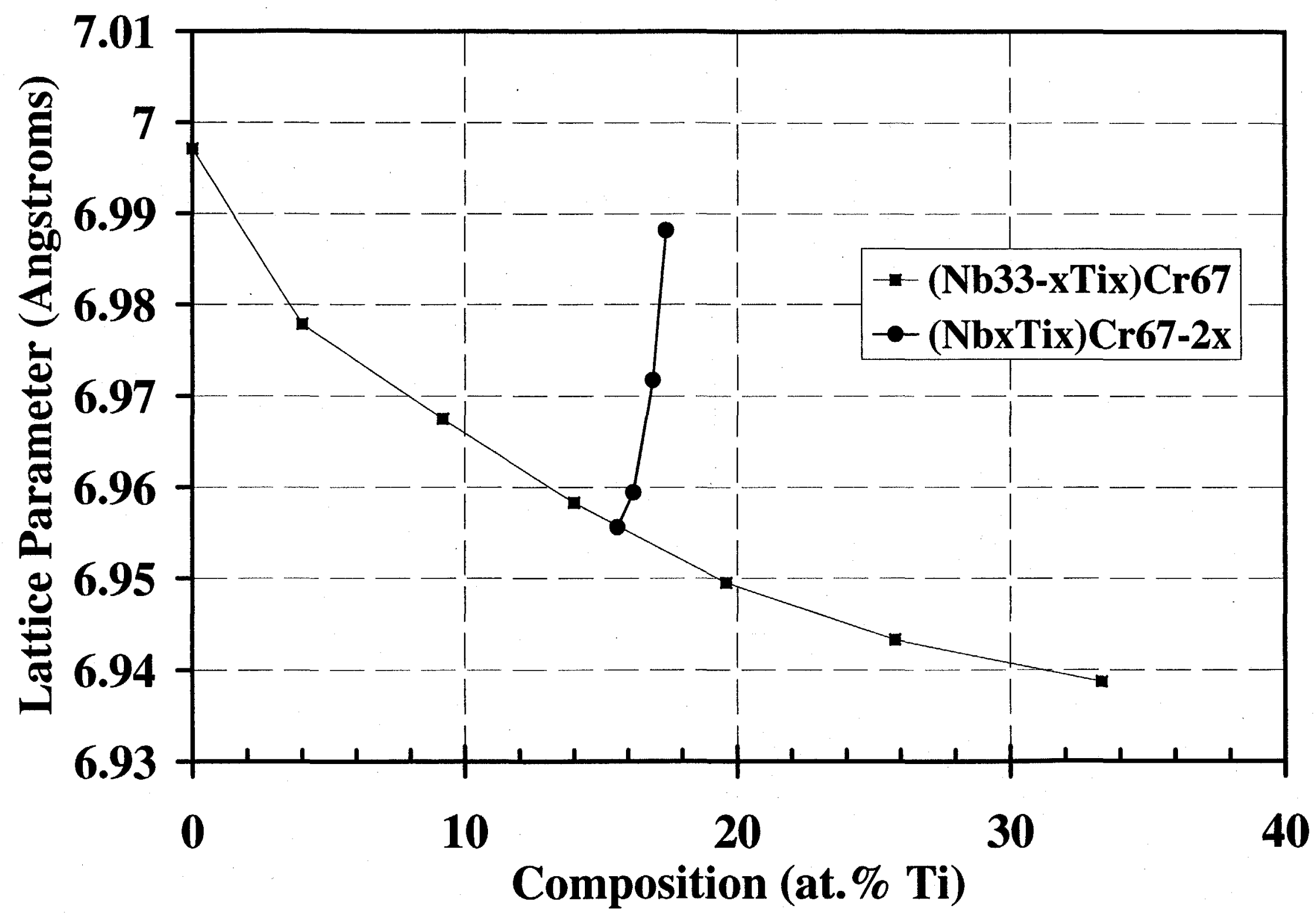




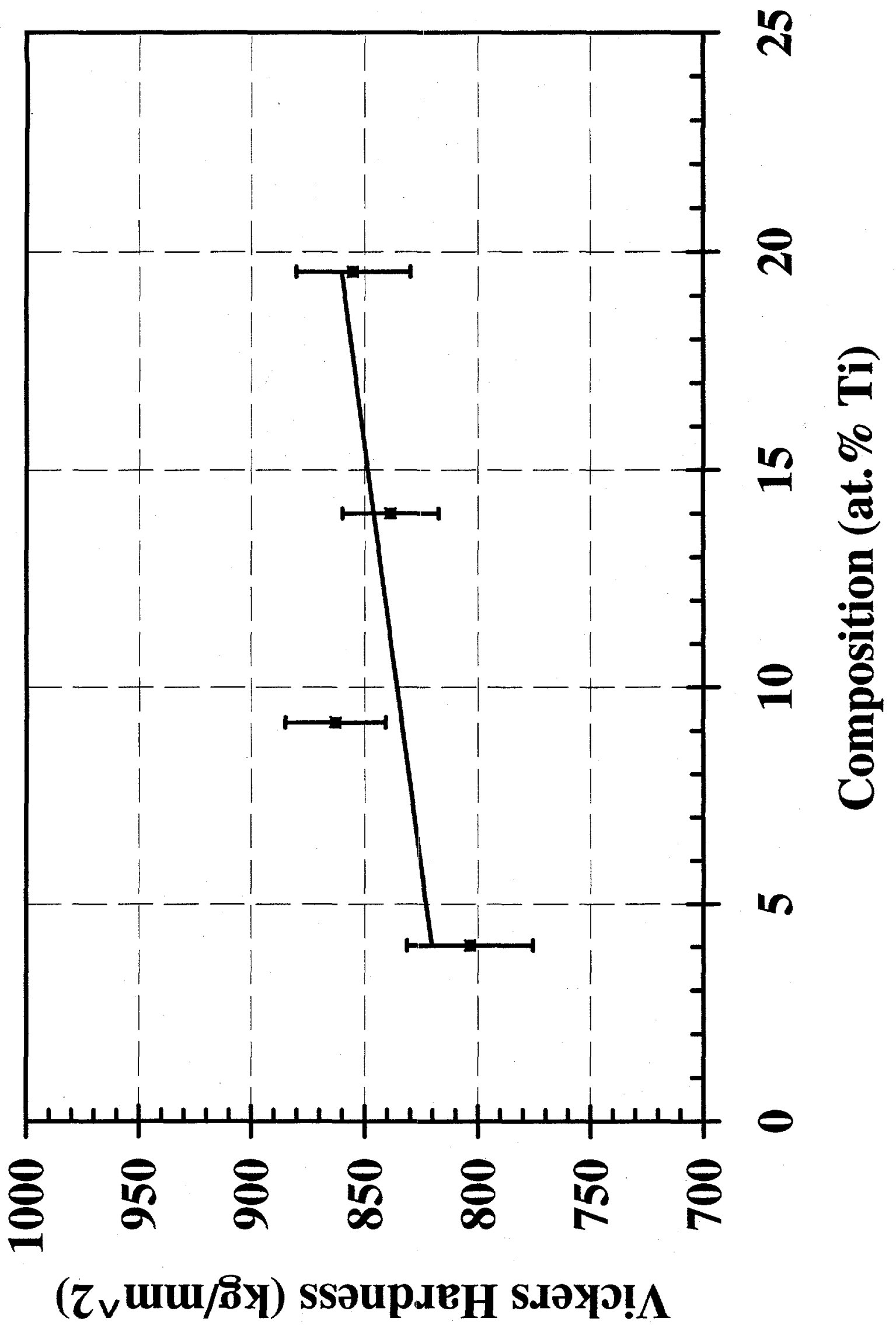




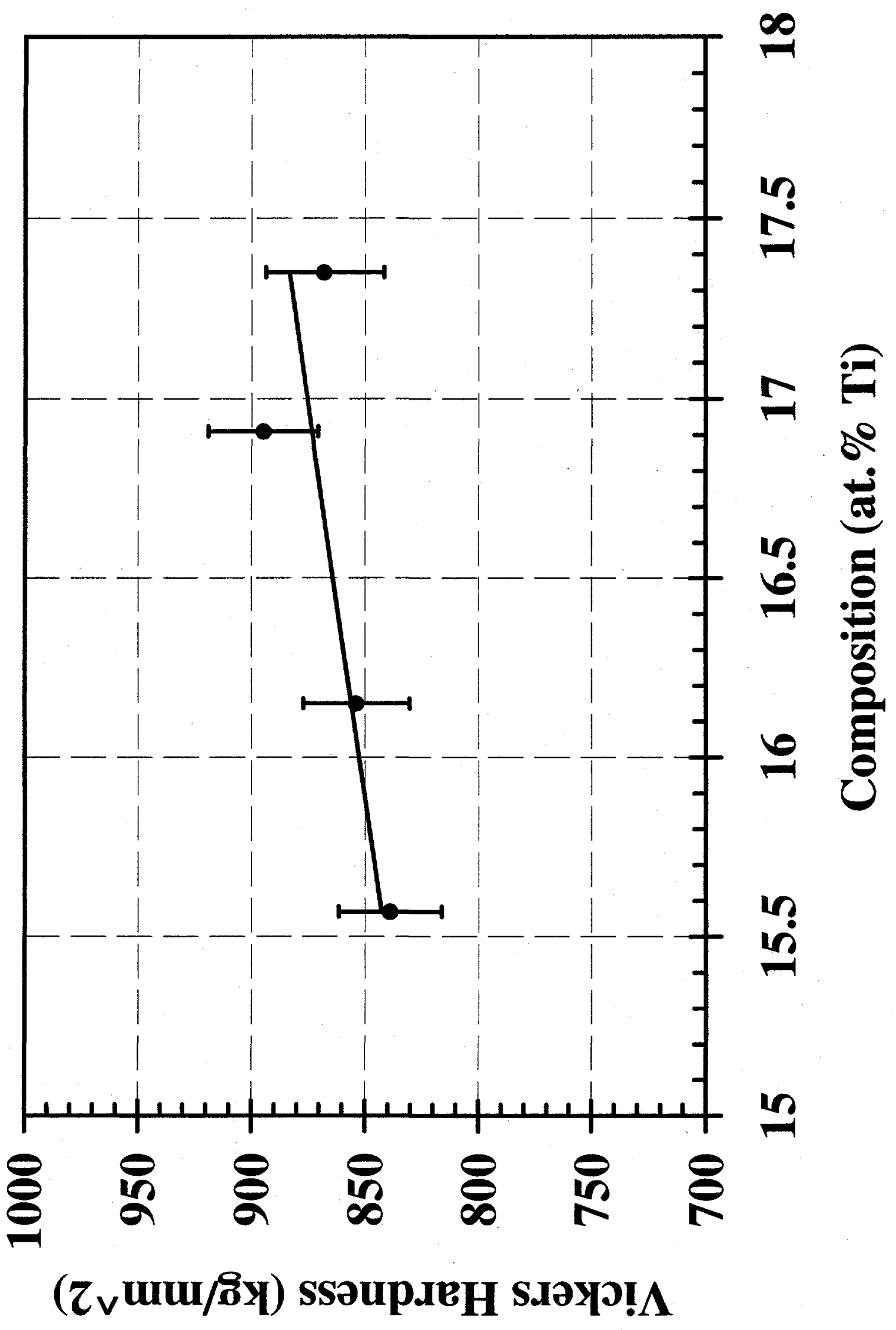




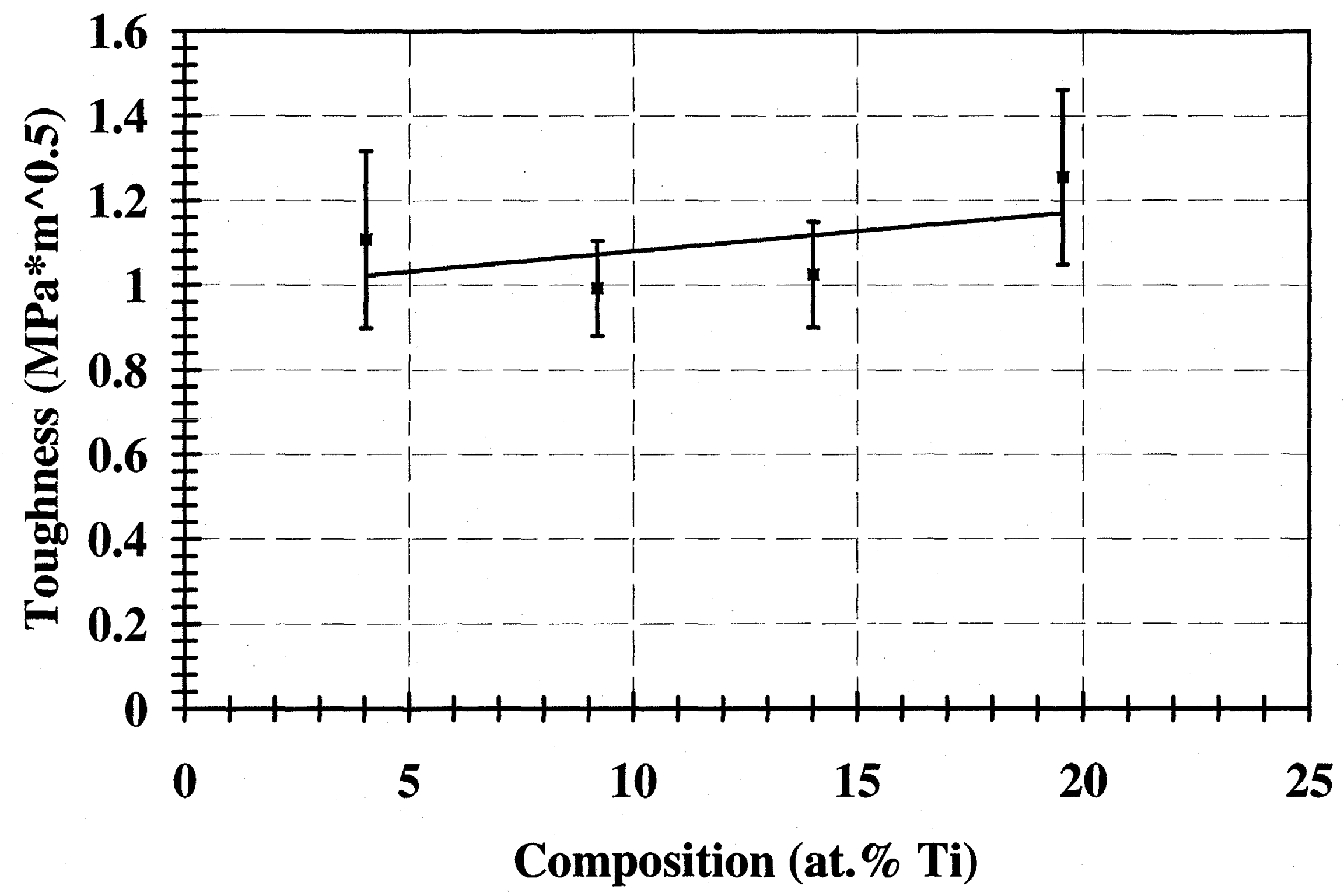




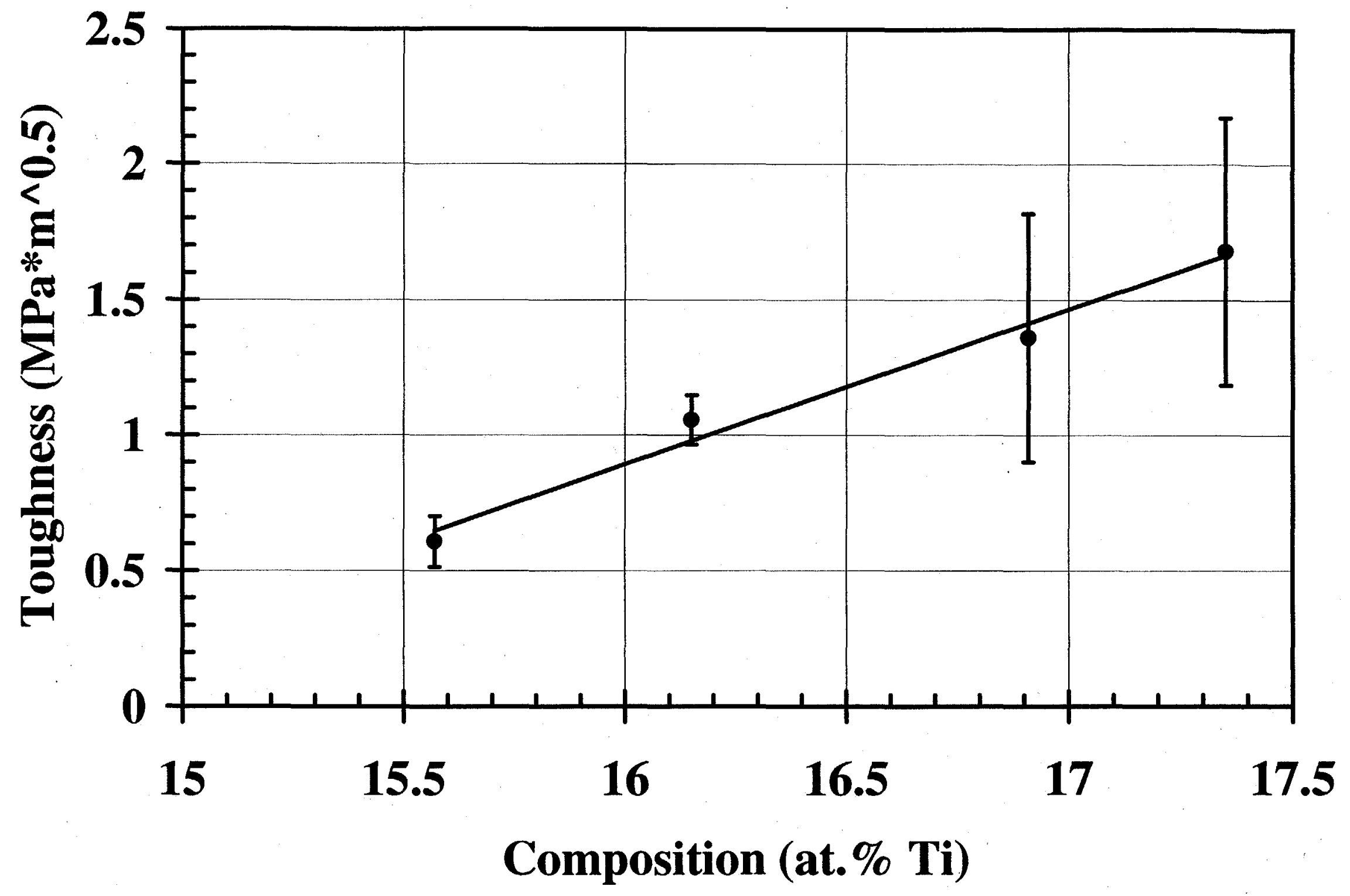




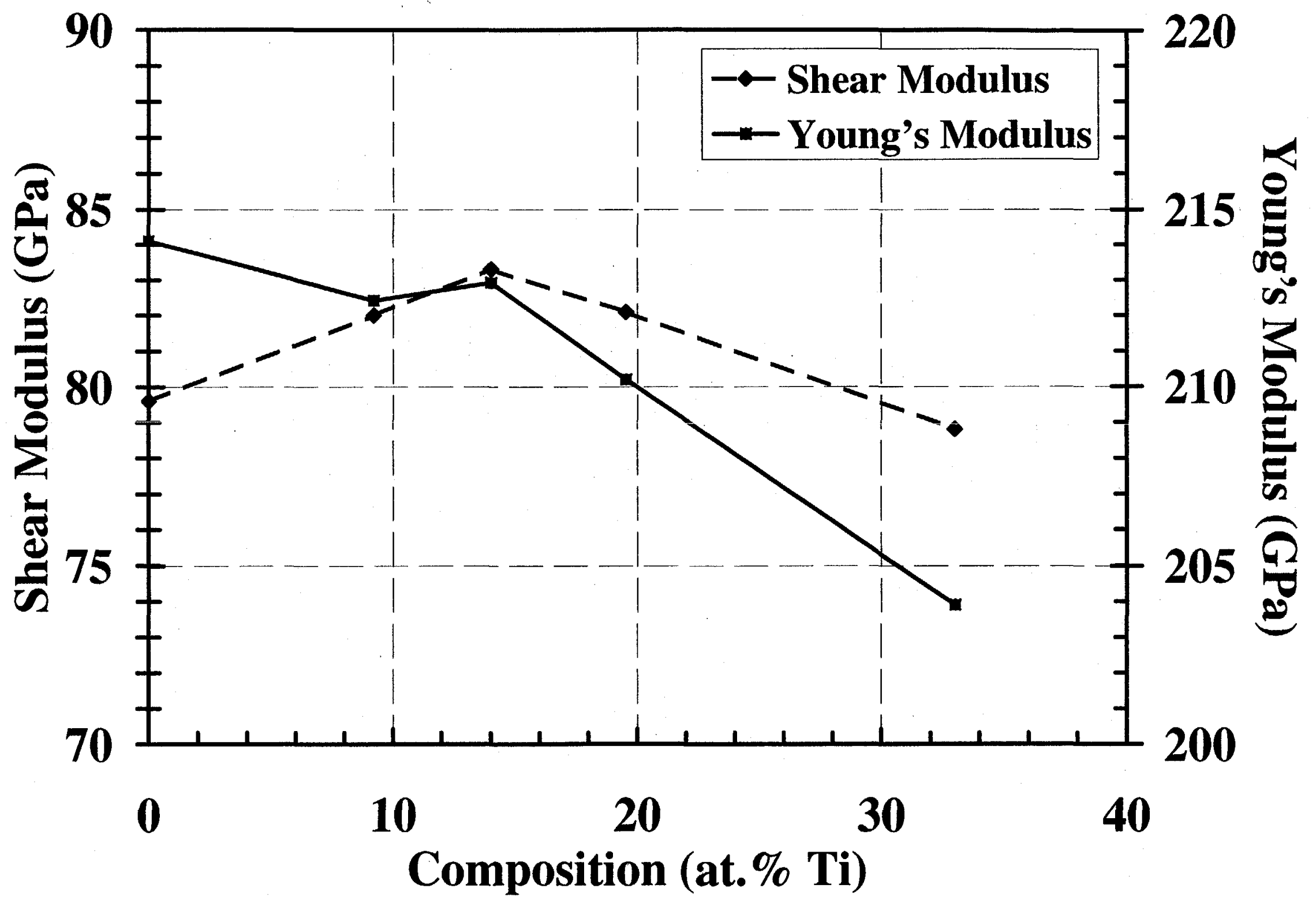




\section{Young's Modulus (GPa)}

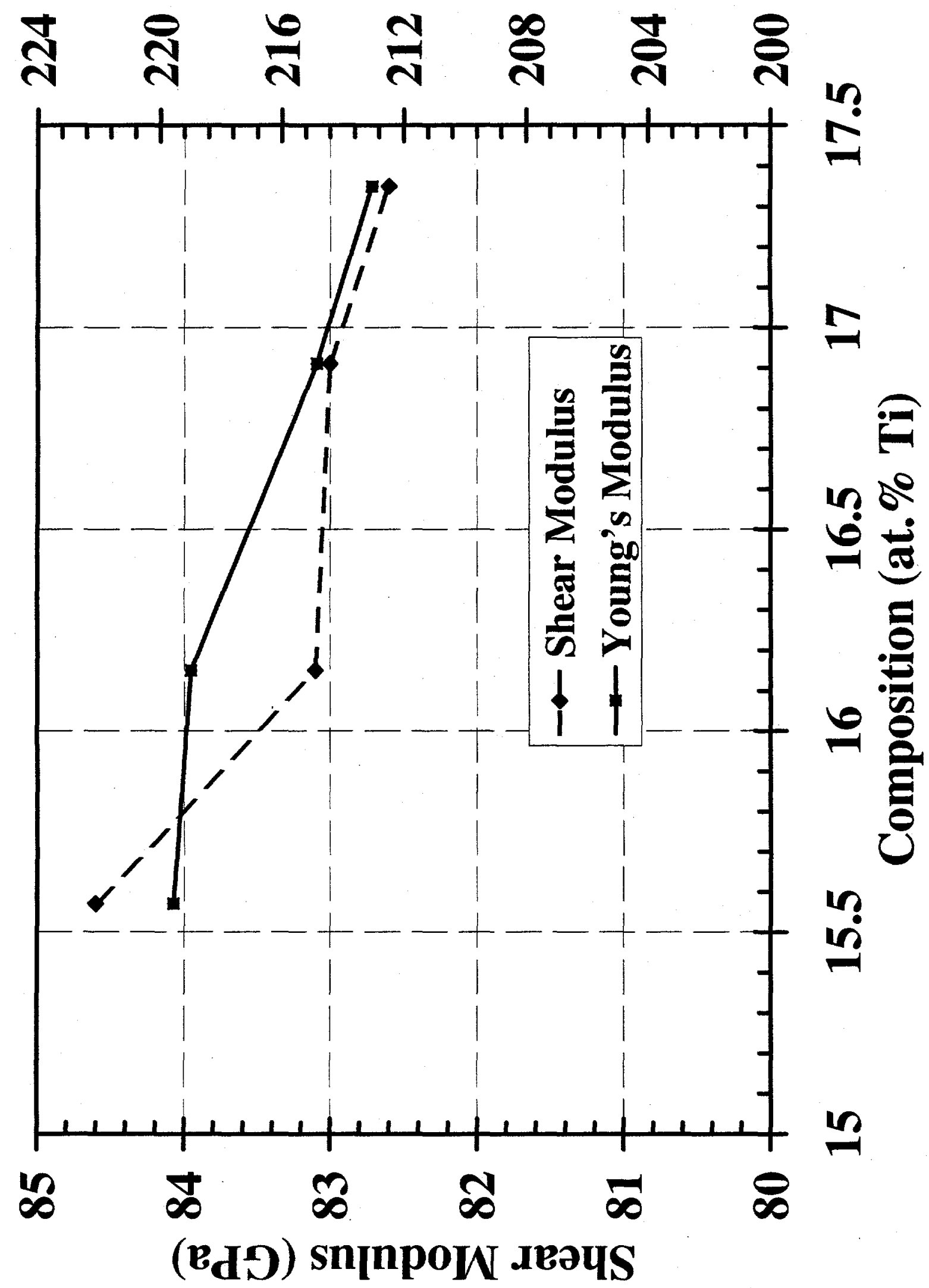



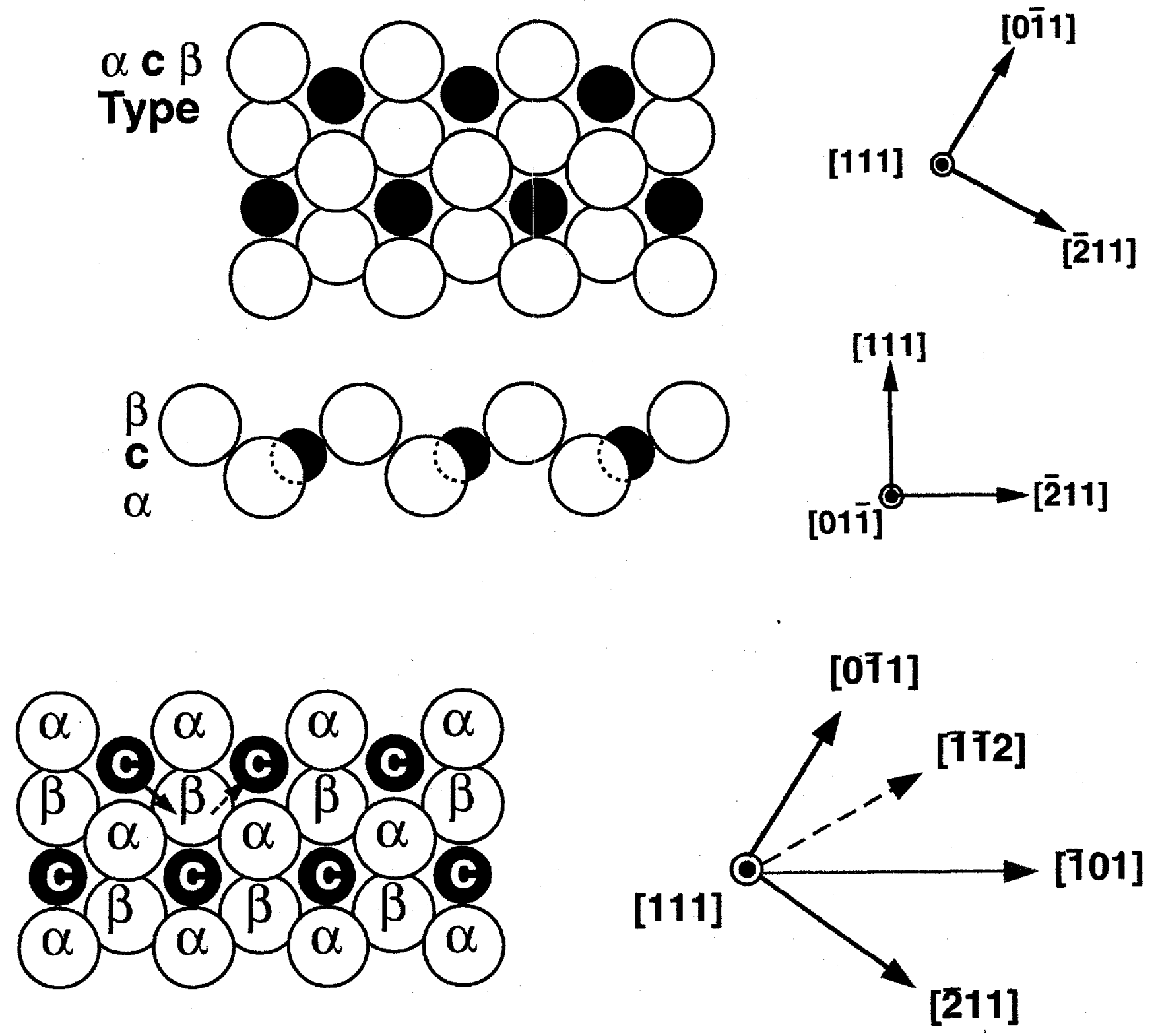